\title{
Locally Advanced and Metastatic Prostate Cancer Treated with Intermittent Androgen Monotherapy or Maximal Androgen Blockade: Results from a Randomised Phase 3 Study by the South European Uroncological Group
}

\author{
Fernando Calais da Silva $^{a, *}$, Fernando Manuel Calais da Silva ${ }^{b}$, Frederico Gonçalves ${ }^{c}$, \\ Américo Santos $^{d}$, Jan Kliment ${ }^{e}$, Peter Whelan ${ }^{f}$, Tim Oliver ${ }^{g}$, Nicos Antoniou $^{h}$, Spiro Pastidis ${ }^{h}$, \\ Anton Marques Queimadelos ${ }^{i}$, Chris Robertson ${ }^{j, k, l}$ \\ a Department of Urology, Centro Hospitalar Lisboa Central, Lisbon, Portugal; ' Department of Urology, Centro Hospitalar Lisboa Central, Lisbon, Portugal; \\ ${ }^{\mathrm{c}}$ Department of Urology, Klinika Lfuk, Bratislava, Slovakia; ${ }^{\mathrm{d}}$ Department of Urology, Hospital S. Marcos, Braga, Portugal; ${ }^{\mathrm{e}}$ Department of Urology, Jessenius \\ School of Medicine, Martin, Slovakia; ${ }^{\mathrm{f}}$ Department of Urology, Saint James University Hospital, Leeds, UK; ${ }^{\mathrm{g}}$ Department of Urology, Saint Bartholomew's, \\ London, UK; ${ }^{\text {h }}$ Department of Urology, Amalia Fleming Hospital, Melissa, Greece; i Department of Urology, Policlinico La Rosaleda, Santiago de Compostela, \\ Spain; ${ }^{j}$ Department of Mathematics and Statistics, University of Strathclyde, Glasgow, UK; ${ }^{\mathrm{k}}$ Health Protection Scotland, Glasgow, UK; ${ }^{1}$ International \\ Prevention Research Institute, Lyon, France
}

\section{Article info}

Article history:

Accepted March 25, 2013

Published online ahead of print on April 4, 2013

\section{Keywords:}

Maximal androgen blockade Intermittent antiandrogen therapy

Prostate cancer

\begin{abstract}
Background: Few randomised studies have compared antiandrogen intermittent hormonal therapy (IHT) with continuous maximal androgen blockade (MAB) therapy for advanced prostate cancer (PCa). Objective: To determine whether overall survival (OS) on IHT (cyproterone acetate; $\mathrm{CPA}$ ) is noninferior to OS on continuous MAB.

Design, setting, and participants: This phase 3 randomised trial compared IHT and continuous MAB in patients with locally advanced or metastatic PCa.

Intervention: During induction, patients received CPA $200 \mathrm{mg} / \mathrm{d}$ for $2 \mathrm{wk}$ and then monthly depot injections of a luteinising hormone-releasing hormone (LHRH; triptoreline $11.25 \mathrm{mg}$ ) analogue plus CPA $200 \mathrm{mg} / \mathrm{d}$. Patients whose prostate-specific antigen (PSA) was $<4 \mathrm{ng} / \mathrm{ml}$ after 3 mo of induction treatment were randomised to the IHT arm (stopped treatment and restarted on CPA $300 \mathrm{mg} / \mathrm{d}$ monotherapy if PSA rose to $\geq 20 \mathrm{ng} / \mathrm{ml}$ or they were symptomatic) or the continuous arm (CPA $200 \mathrm{mg} / \mathrm{d}$ plus monthly LHRH analogue).

Outcome measurements and statistical analysis: Primary outcome measurement was OS. Secondary outcomes included cause-specific survival, time to subjective or objective progression, and quality of life. Time off therapy in the intermittent arm was recorded.

Results and limitations: We recruited 1045 patients, of which 918 responded to induction therapy and were randomised ( 462 to IHT and 456 to continuous MAB). OS was similar between groups $(p=0.25)$, and noninferiority of IHT was demonstrated (hazard ratio [HR]: 0.90; 95\% confidence interval [CI], $0.76-1.07)$. There was a trend for an interaction between PSA and treatment $(p=0.05)$, favouring IHT over continuous therapy in patients with PSA $\leq 1 \mathrm{ng} / \mathrm{ml}$ (HR: $0.79 ; 95 \% \mathrm{Cl}, 0.61-1.02$ ). Men treated with IHT reported better sexual function. Among the 462 patients on IHT, $50 \%$ and $28 \%$ of patients were off therapy for $\geq 2.5 \mathrm{yr}$ or $>5 \mathrm{yr}$, respectively, after randomisation. The main limitation is that the length of time for the trial to mature means that other therapies are now available. A second limitation is that T3 patients may now profit from watchful waiting instead of androgen-deprivation therapy. Conclusions: Noninferiority of IHT in terms of survival and its association with better sexual activity than continuous therapy suggest that IHT should be considered for use in routine clinical practice.

(C) 2013 European Association of Urology. Published by Elsevier B.V. All rights reserved.
\end{abstract}

* Corresponding author. Lisboa University, SEUG, Av. 5 de Outubro,72 6 ${ }^{\circ}$ B - 1050-059 Lisbon, Portugal. Tel. +35 1217996490

E-mail address: secretariado@seug-gpgu.org (F.C. da Silva). 


\section{Introduction}

Prostate cancer (PCa) is one of the most commonly diagnosed cancers in men [1]. Incidence in recent years has been increasing worldwide and is expected to continue with the current ageing population; this increase poses a global major health and economic burden on society. Intermittent hormonal therapy (IHT) with antiandrogens is used increasingly to improve the quality of life (QoL) of PCa patients without diminishing the efficacy of chronic androgen-deprivation therapy (ADT). ADT is the current standard therapy for advanced PCa or cancer that has metastasised beyond the prostate. To maximise the efficacy and tolerability of ADT while reducing adverse events, it is possible for some patients to alternate treatment and offtreatment periods.

Few randomised studies have compared the efficacy of IHT with continuous therapy; however, available data suggest that IHT is at least as effective as continuous treatment in the management of advanced PCa with regard to both disease progression and overall survival (OS) [2-5]. Further potential benefits of IHT include reduced sideeffects compared with continuous therapy, improved QoL (especially recovery of sexual potency), health care cost savings, and delayed emergence of hormonal refractoriness [6-8]. However, no randomised studies to date have assessed IHT delivered as monotherapy with antiandrogens (cyproterone acetate; CPA).

This study aimed to demonstrate the noninferiority of antiandrogen monotherapy with CPA IHT compared with continuous maximal androgen blockade (MAB) therapy.

The European Association of Urology recently acknowledged that intermittent ADT (IADT) is already offered to patients with advanced PCa and stated in its guidelines that IADT should no longer be considered experimental [1].

\section{Patients and methods}

South European Uroncological Group (SEUG) 9901, a phase 3 randomised trial, compared intermittent and continuous androgen suppression with respect to OS, time to loss of androgen dependence, symptom-free survival, and QoL. Patients were recruited in 31 centres in Portugal, Spain, Italy, Turkey, Greece, Slovakia, and the United Kingdom. All patients gave informed consent. The study opened in September 1999, with the first patient randomised in January 2000 and the last patient randomised in September 2007. Follow-up for this analysis ceased in October 2012.

\subsection{Patients}

Inclusion criteria were histologically confirmed prostate adenocarcinoma, cT3-cT4 M0 and M1, serum prostate-specific antigen (PSA) $\geq 4 \mathrm{ng} / \mathrm{ml}$ and $\leq 100 \mathrm{ng} / \mathrm{ml}$, age $\leq 80 \mathrm{yr}$, World Health Organisation performance status $0-2$, and normal liver function not suitable for definitive treatment. Exclusion criteria were previous hormonal therapy or chemotherapy, presence of another neoplasm (except skin, excluding melanoma), severe concomitant chronic disease, or expected follow-up difficulties. Prior surgery and radiotherapy were reasons for exclusion. Clinical stage was assessed by the investigator in each centre, and there was no central pathology review.

\subsection{Intervention}

All patients received induction therapy of CPA $200 \mathrm{mg} / \mathrm{d}$ for $2 \mathrm{wk}$, followed by monthly depot injections of a luteinising hormone-releasing hormone (LHRH) agonist (triptoreline $11.25 \mathrm{mg}$ ) plus CPA $200 \mathrm{mg} / \mathrm{d}$. Patients whose PSA levels decreased to $<4 \mathrm{ng} / \mathrm{ml} 14$ wk after starting induction therapy were randomised to receive either IHT or continuous antiandrogen therapy. Patients randomised to the continuous arm received CPA $200 \mathrm{mg} / \mathrm{d}$ plus monthly LHRH agonist, whereas those randomised to the IHT arm ceased treatment. Monotherapy with CPA $300 \mathrm{mg} / \mathrm{d}$ was restarted in the IHT arm if the PSA level rose to $\geq 20 \mathrm{ng} / \mathrm{ml}$ or if the patient experienced symptoms attributable to PCa.

Patients in both arms discontinued when there was evidence of objective progression (distant metastases or new metastatic sites) or subjective progression. Subjective progression was defined as the presence of at least two of the following three criteria: (1) biochemical progression, defined as an increase of the PSA level by $20 \%$ on two successive occasions at least $1 \mathrm{mo}$ apart; (2) an increase in pain by two increments; or (3) worsening of performance status by two increments. QoL was assessed every 6 mo and in the intermittent arm when therapy was restarted, using the European Organisation for Research and Treatment of Cancer (EORTC) QLQ-C30 questionnaire and the Prostate Cancer Module.

\subsection{Statistical analysis}

The primary aim of the study was to demonstrate noninferiority of intermittent CPA therapy compared with continuous MAB in terms of OS. For continuous therapy, it was assumed that M0 and M1 patients had median survival of $5 \mathrm{yr}$ and $2.9 \mathrm{yr}$, respectively. Assuming that approximately $65 \%$ and $35 \%$ of patients would have been M0 and M1, respectively, then the median survival time for the entire group of patients on continuous MAB was expected to be approximately $4.25 \mathrm{yr}$. Intermittent CPA therapy was considered to be noninferior to continuous $M A B$ if median survival was no worse than $3.5 \mathrm{yr}$, which corresponds to an increase of $20 \%$ in the hazard ratio (HR; 1.21 ). Based on a one-sided log-rank test for noninferiority at error rates $\alpha=0.05$ and $\beta=0.20$, a total of 658 deaths were required for statistical analysis. With an entry rate of 150 patients per year and a follow-up period of $5 \mathrm{yr}$ after the last patient had been entered, randomisation of 900 patients over 6 yr was planned.

Statistical analysis was carried out using R v.2.15 (R Foundation, Vienna, Austria). Chi-square tests were used to test the association between treatment and the percentage of patients with side effects. Kaplan-Meier curves were used to estimate the time to death and progression-free survival (PFS) and were compared using the two-sided log-rank test and a Cox proportional hazards model. Median survival was estimated from the Kaplan-Meier curve. HRs were expressed as intermittent therapy compared with continuous therapy, and a $95 \%$ confidence interval (CI) was used. The null hypothesis (HR: 1.21; specifying noninferiority) versus the alternative (HR: 1) was used for the main outcome of OS and a one-sided test. Cox regression models were used to account for the effect of prognostic factors. Cause-specific deaths were analysed by assessing competing risks $[9,10]$ using the cmprsk library in R v.2.2-2 ( $\mathrm{R}$ Foundation, Vienna, Austria). Mixed-effect regression models were used to investigate the trends in PSA and QoL scores during the course of the study. Results are reported at the $5 \%$ significance level, and $95 \%$ CIs are used for all estimated effects. The Benjamini and Hochberg procedure [16] was used to adjust for multiple testing of the subscores in the QoL analysis.

\section{Results}

In total, 1045 patients were recruited and 918 patients were randomised, 462 to IHT and 456 to continuous 
Table 1 - Patient characteristics at randomisation

\begin{tabular}{|c|c|c|c|c|}
\hline & \multicolumn{2}{|c|}{ Intermittent } & \multicolumn{2}{|c|}{ Continuous } \\
\hline & $n$ & $\%$ & $n$ & $\%$ \\
\hline Total & 462 & - & 456 & - \\
\hline \multicolumn{5}{|l|}{ Age group } \\
\hline$<65 \mathrm{yr}$ & 58 & 12.6 & 52 & 11.4 \\
\hline $65-69 \mathrm{yr}$ & 72 & 15.6 & 83 & 18.2 \\
\hline $70-74 \mathrm{yr}$ & 152 & 32.9 & 154 & 33.8 \\
\hline $75-79$ yr & 157 & 34.0 & 149 & 32.7 \\
\hline$\geq 80 \mathrm{yr}$ & 23 & 5.0 & 18 & 3.9 \\
\hline \multicolumn{5}{|l|}{ WHO performance status } \\
\hline 0 & 419 & 90.7 & 413 & 90.6 \\
\hline 1 & 38 & 8.2 & 36 & 7.9 \\
\hline 2 & 2 & 0.4 & 6 & 1.3 \\
\hline \multicolumn{5}{|l|}{ Tumour stage } \\
\hline $\mathrm{T} 2$ & 15 & 3.2 & 20 & 4.4 \\
\hline T3 & 416 & 90.0 & 417 & 91.4 \\
\hline $\mathrm{T} 4$ & 31 & 6.7 & 19 & 4.2 \\
\hline \multicolumn{5}{|l|}{ Histology } \\
\hline Biopsy & 440 & 95.2 & 440 & 96.5 \\
\hline TUR & 20 & 4.3 & 16 & 3.5 \\
\hline Not available & 2 & 0.4 & 0 & 0 \\
\hline \multicolumn{5}{|l|}{ Tumour grade } \\
\hline G1 & 23 & 5.0 & 25 & 5.5 \\
\hline G2 & 314 & 68.0 & 322 & 70.6 \\
\hline $\mathrm{G} 3 / \mathrm{X}$ & 125 & 27.1 & 109 & 23.9 \\
\hline \multicolumn{5}{|l|}{ Gleason score } \\
\hline $2-4$ & 28 & 6.1 & 24 & 5.3 \\
\hline $5-6$ & 186 & 40.3 & 170 & 37.3 \\
\hline $7-8$ & 223 & 48.3 & 235 & 51.5 \\
\hline$\geq 9$ & 25 & 5.4 & 27 & 5.9 \\
\hline \multicolumn{5}{|l|}{ Bone scan } \\
\hline Normal & 355 & 76.8 & 343 & 75.2 \\
\hline $1-6$ hot spots & 42 & 9.1 & 43 & 9.4 \\
\hline$\geq 6$ hot spots & 7 & 1.5 & 2 & 0.4 \\
\hline Other abnormalities & 39 & 8.4 & 46 & 10.1 \\
\hline Not carried out & 19 & 4.1 & 22 & 4.8 \\
\hline \multicolumn{5}{|l|}{ Metastatic status } \\
\hline M0 & 410 & 88.7 & 406 & 89 \\
\hline M1 & 52 & 11.3 & 50 & 11 \\
\hline \multicolumn{5}{|c|}{ Associated chronic disease } \\
\hline Any & 122 & 28.4 & 121 & 28.4 \\
\hline MI & 22 & 4.8 & 24 & 5.3 \\
\hline DVT & 8 & 1.7 & 3 & 0.7 \\
\hline CVA & 21 & 4.5 & 18 & 3.9 \\
\hline Respiratory & 24 & 5.2 & 21 & 4.6 \\
\hline Other & 2 & 0.4 & 2 & 0.4 \\
\hline OACD & 70 & 15.2 & 70 & 15.4 \\
\hline \multicolumn{5}{|l|}{ PSA level } \\
\hline$<1 \mathrm{ng} / \mathrm{ml}$ & 229 & 49.6 & 242 & 53.1 \\
\hline $1-2 \mathrm{ng} / \mathrm{ml}$ & 102 & 22.1 & 74 & 16.2 \\
\hline$>2-4 \mathrm{ng} / \mathrm{ml}$ & 131 & 28.4 & 140 & 30.7 \\
\hline
\end{tabular}

treatment. Patient and disease characteristics at randomisation are shown in Table 1 . The patient distribution was similar in the two treatment groups (Table 1). The median PSA level at recruitment (before induction therapy) of patients that were subsequently randomised was $15 \mathrm{ng} / \mathrm{ml}$ and then $1.4 \mathrm{ng} / \mathrm{ml}$ after the induction period, with $31 \%$ having PSA $\leq 0.5 \mathrm{ng} / \mathrm{ml}$. PSA level, Gleason score, and metastatic status at baseline were the only independent predictors of PSA level at randomisation; T stage, tumour grade, and age had no effect. PSA level at randomisation increased with higher baseline Gleason scores: Gleason score 2-4, median PSA level $0.6 \mathrm{ng} / \mathrm{ml}$; Gleason score 5-6, median PSA level $0.7 \mathrm{ng} / \mathrm{ml}$; Gleason score 7-8, median PSA level $1.2 \mathrm{ng} / \mathrm{ml}$; Gleason score 9-10, median PSA level $1.6 \mathrm{ng} / \mathrm{ml}$ $(p<0.001)$.

The median follow-up time from randomisation was 66 mo (maximum: $12 \mathrm{yr}$ ), and 56\% of patients were observed for $>5 \mathrm{yr}$; 393 patients were alive at the last follow-up. Progression was reported in 299 patients, 168 in the IHT arm and 131 in the continuous arm (Table 2). 
Table 2 - Patients alive, lost to follow-up, dead, with cause of death and progression by treatment arm

\begin{tabular}{|c|c|c|c|c|c|c|c|c|}
\hline & \multicolumn{2}{|c|}{$\begin{array}{l}\text { Intermittent } \\
\text { treatment }\end{array}$} & \multicolumn{2}{|c|}{$\begin{array}{l}\text { Continuous } \\
\text { treatment }\end{array}$} & \multicolumn{3}{|c|}{$95 \% \mathrm{CI}$} & \multirow{2}{*}{$\begin{array}{l}p \\
-\end{array}$} \\
\hline & $n$ & $\%$ & $n$ & $\%$ & HR & Lower & Upper & \\
\hline Randomised & 462 & - & 456 & - & - & - & - & - \\
\hline Alive at last contact & 204 & 44.2 & 189 & 41.4 & - & - & - & - \\
\hline Lost to follow-up & 11 & 2.4 & 11 & 2.4 & - & - & - & - \\
\hline Any progression & 168 & 36.4 & 131 & 28.7 & 1.16 & 0.93 & 1.47 & 0.195 \\
\hline Dead & 258 & 55.8 & 267 & 58.6 & 0.90 & 0.76 & 1.07 & 0.252 \\
\hline Cancer & 103 & 22.3 & 96 & 21.1 & 1.00 & 0.76 & 1.32 & 0.995 \\
\hline Prostate cancer & 82 & 17.7 & 82 & 18 & 0.93 & 0.69 & 1.26 & 0.648 \\
\hline Second primary & 21 & 4.5 & 14 & 3.1 & 1.41 & 0.71 & 2.75 & 0.332 \\
\hline Cardiovascular death & 107 & 23.2 & 122 & 26.8 & 0.83 & 0.64 & 1.07 & 0.152 \\
\hline Other/unknown & 48 & 10.4 & 49 & 10.7 & 0.91 & 0.61 & 1.36 & 0.650 \\
\hline
\end{tabular}

Among patients with complete information on progression, there were slightly more progressions among those on IHT (HR: 1.16; 95\% Cl, 0.93-1.47; $p=0.20$ ).

Overall, 525 patients died, 258 in the IHT arm and 267 in the continuous arm. There was no significant difference in OS on intermittent therapy (HR: $0.90 ; 95 \% \mathrm{CI}, 0.76-1.07$; $p=0.99$ [one-sided test]) (Table 2, Fig. 1). The upper 95\% confidence limit is less than the 1.21 limit specified in the
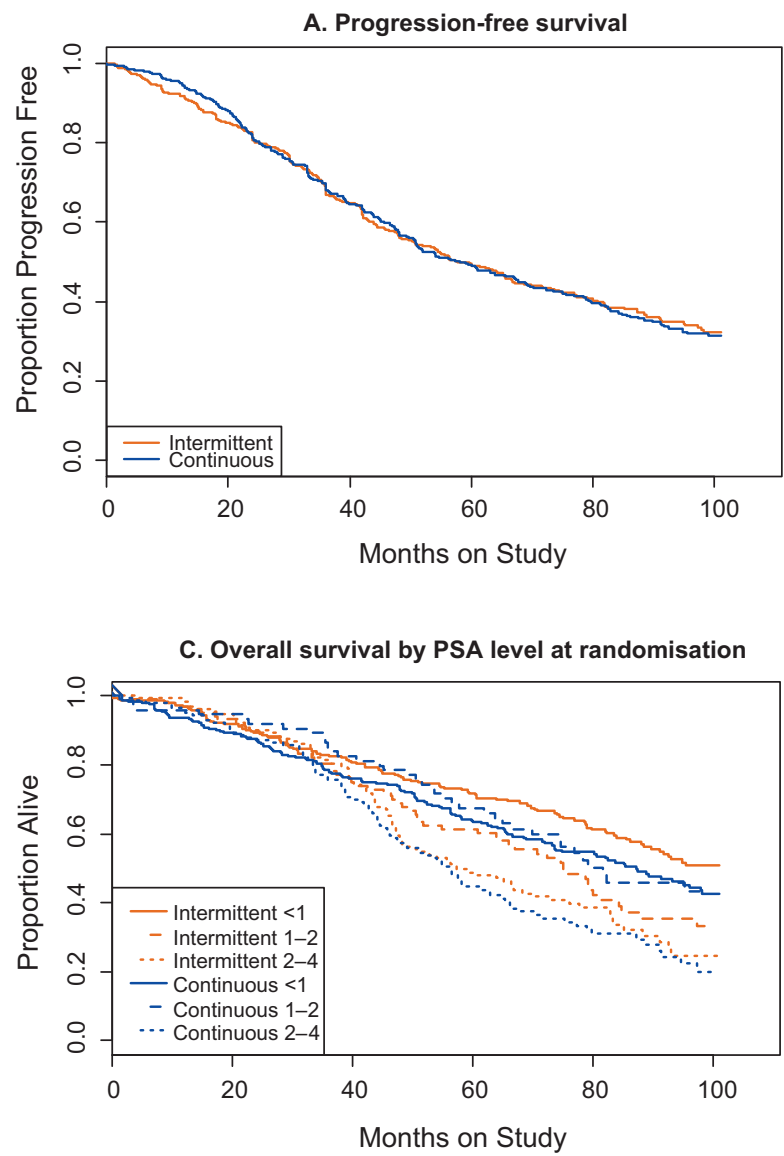

design demonstrating noninferiority of IHT relative to continuous treatment. Both PSA and metastatic status at randomisation were independently associated with survival (Fig. 1), and there was evidence of a trend for an interaction of PSA with treatment ( $p=0.05)$; intermittent therapy was more effective than continuous therapy among patients with PSA $\leq 1 \mathrm{ng} / \mathrm{ml}$ (HR: 0.79; 95\% CI, 0.61-1.02, $p=0.07)$.
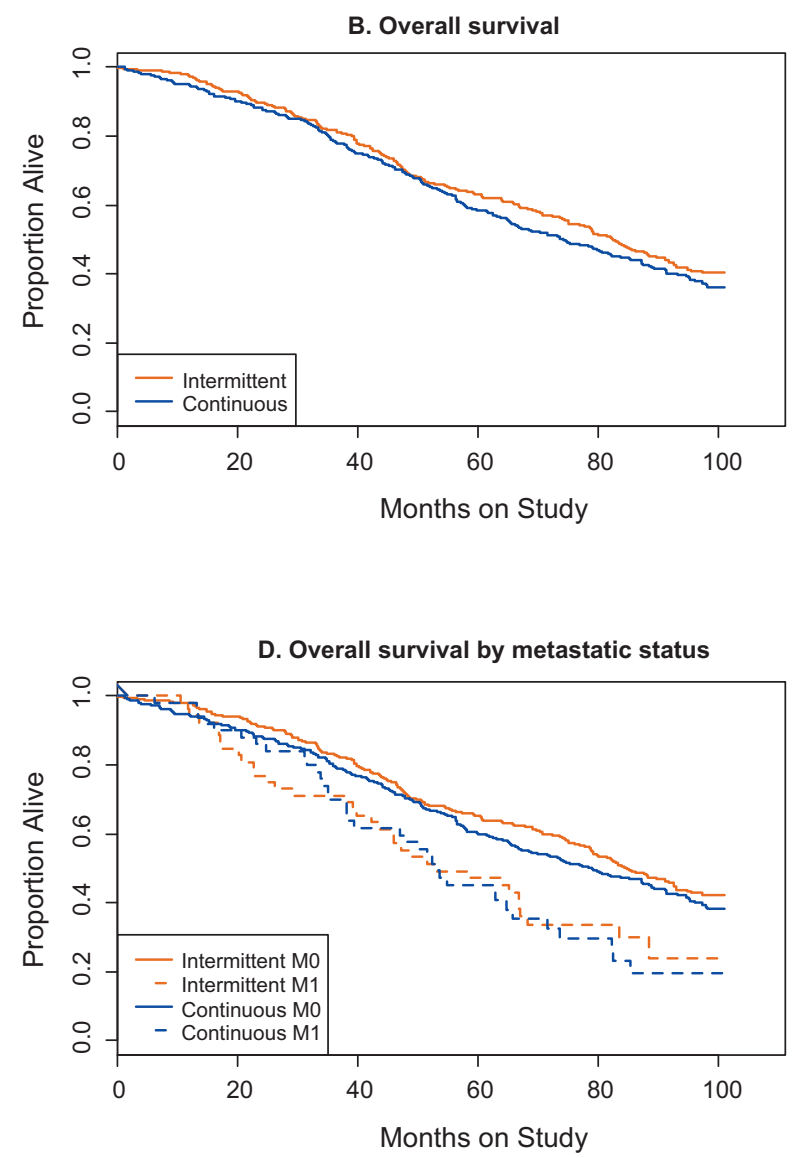

Fig. 1 - Kaplan-Meier curves for the time to any progression and time to death. The continuous arm is shown using green lines, and the intermittent arm is shown with black lines: (a) progression-free survival; (b) overall survival; (c) overall survival by prostate-specific antigen (PSA) level at randomisation; (d) overall survival by metastatic status. 
Table 3 - Hazard ratios (HR) and 95\% confidence intervals (lower and upper) from (a) the cox model for progression free survival and (b) the competing risks model for the cause of death

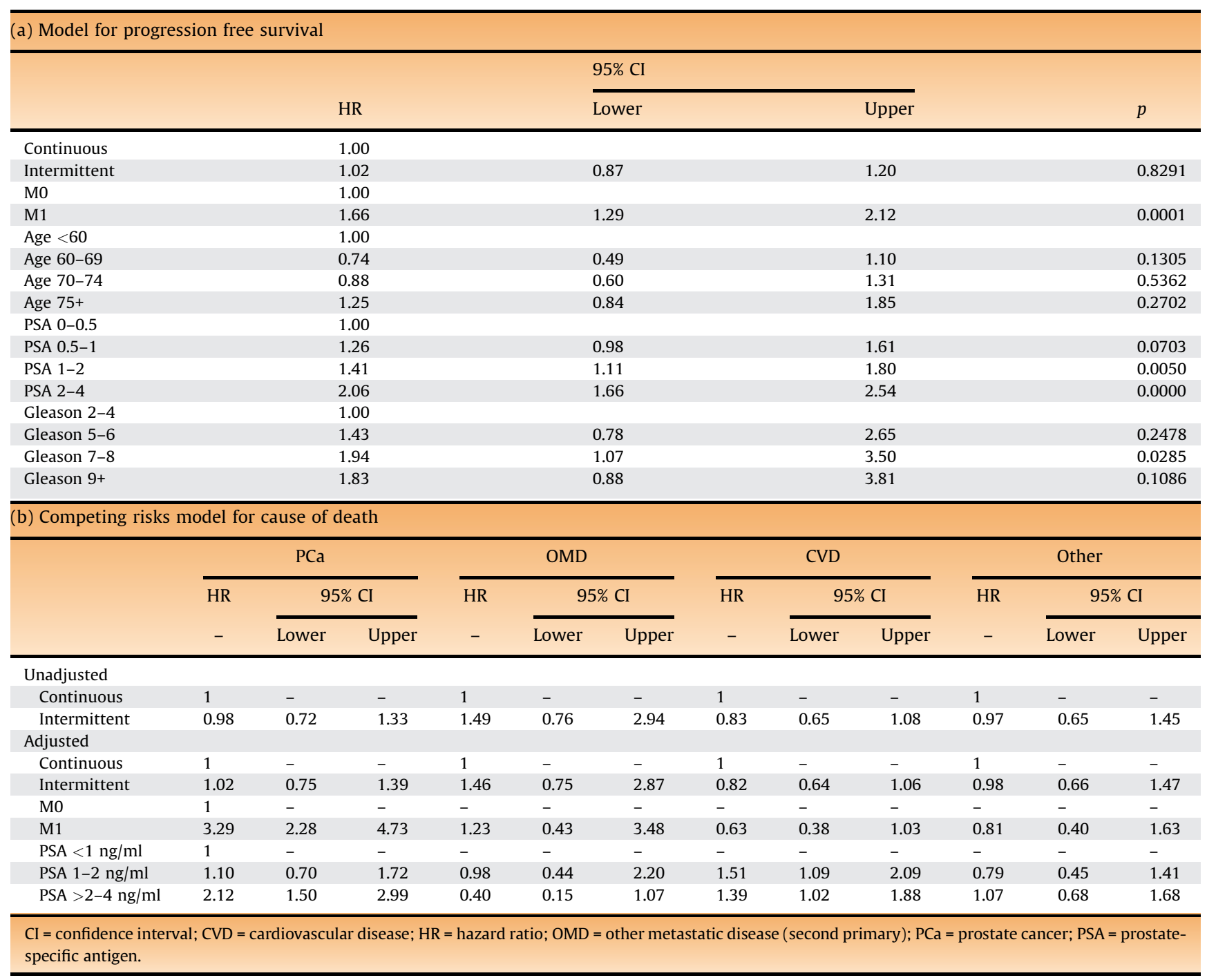

Another 69 patients, 25 on continuous therapy and 44 on IHT, progressed but were still alive at the time the analysis took place. There was no evidence of any difference between continuous therapy and IHT in terms of PFS (HR: $1.01 ; 95 \% \mathrm{CI}, 0.86-1.19 ; p=0.89$ ). Metastatic status, age, PSA, and Gleason score were all independently associated with PFS (Table 3a).

The number of deaths due to any cancer, $\mathrm{PCa}$, second primary cancer/other malignant disease (OMD), cardiovascular death (CVD), and other/unknown causes were similar between treatment arms (Table 2). The competing risks analysis showed that the slightly reduced hazard of dying in the group on IHT resulted primarily from fewer deaths from CVD balanced by an increased risk of death from a second primary cancer (Table $3 b$ ). None of these differences in HR was statistically significant (Table $3 b$ ).

Both metastatic status and PSA level at randomisation were associated with death from PCa but not with OMD or other causes of death (Table $3 \mathrm{~b}$ ). Adjusting for metastatic status and PSA at randomisation, the HR of dying from one of the four causes was similar to the unadjusted values.

\subsection{Safety and quality of life}

Side effects were generally reported more frequently among patients on continuous therapy (Table 4). Summary QLQC30 totals were similar between study arms (2.1 points

Table 4 - Patients reporting specified side effects at least once during follow-up by treatment arm

\begin{tabular}{lccc}
\hline & $\begin{array}{c}\text { Intermittent } \\
\text { treatment }\end{array}$ & $\begin{array}{c}\text { Continuous } \\
\text { treatment }\end{array}$ & $p$ \\
\cline { 2 - 3 } No. of patients & 436 & 421 & - \\
\hline Side effect & & & \\
$\quad$ Hot flushes & 8.3 & 24.9 & $<0.0001$ \\
Gynaecomastia & 13.8 & 37.3 & $<0.0001$ \\
Headache & 8.0 & 15.9 & 0.0005 \\
Skin complaints & 0.7 & 1.7 & 0.3124 \\
Other & 11.0 & 12.8 & 0.4741 \\
\hline${ }^{2}$ test of the difference between the percentages. & \\
${ }^{*}$ Number of patients with at least one follow-up form completed. \\
\hline
\end{tabular}


Table 5 - Patients and median times on and off therapy (weeks) in the intermittent arm according to prostate-specific antigen level at randomisation

\begin{tabular}{|c|c|c|c|c|c|c|}
\hline & \multicolumn{2}{|r|}{ All patients } & \multicolumn{2}{|c|}{$\mathrm{PSA}<1 \mathrm{ng} / \mathrm{ml}$} & \multicolumn{2}{|c|}{ PSA 1-4 ng/ml } \\
\hline & $n$ & Time, median, wk & $n$ & Time, median, wk & $n$ & Time, median, wk \\
\hline Randomisation to first time on therapy & 454 & 132.0 & 224 & 162.0 & 230 & 110.0 \\
\hline Duration of time on first therapy & 231 & 20.0 & 110 & 16.7 & 121 & 26.0 \\
\hline Duration of second off-therapy period & 165 & 43.0 & 95 & 49.6 & 70 & 33.1 \\
\hline Duration of time on second therapy & 121 & 19.6 & 75 & 18.1 & 46 & 21.1 \\
\hline
\end{tabular}

lower [worse QoL; standard error (SE): 1.27] in the continuous arm compared with the intermittent arm; $p=0.11$ ) during 60 mo of follow-up. QLQ-C30 scores decreased in both arms, from 83.4 (SE: 1.96) at baseline to 70.5 (SE: 0.96) after $60 \mathrm{mo}$, and the gradient of the decline was similar in the two arms $(p=0.94)$. During follow-up, the only differences between the two groups of patients were in relation to the symptoms and sexual activity questions in the EORTC Prostate Cancer Module, with a significantly higher proportion of patients in the continuous arm reporting symptoms of hot flushes, gynaecomastia and swelling of the legs $(p=0.0001)$, and sexual problems $(p=0.003)$. Reported sexual activity decreased in both arms during the study, although sexual activity was significantly greater $(p<0.0001)$ in the IHT arm. Shortly after randomisation, with the majority of patients in the IHT arm off therapy, the level of sexual activity after 6 mo in this group was similar to pretreatment levels (31.3\% and $32.7 \%$, respectively); sexual activity then decreased as progressively more patients in the IHT arm received CPA therapy. However, at 30 mo after randomisation, the proportion of patients reporting sexual activity was significantly greater in the IHT arm than in the continuous arm $(24.9 \%$ of 226 patients vs $6.4 \%$ of 145 patients, respectively; $p<0.0001$ ).

Among the 462 patients randomised to IHT, 50\% were off therapy for at least $2.5 \mathrm{yr}$ following randomisation (Table 5) and $28 \%$ were off-therapy for $>5 \mathrm{yr}$. The median time off therapy for patients whose PSA levels were $\leq 1 \mathrm{ng} / \mathrm{ml}$ and $1-4 \mathrm{ng} / \mathrm{ml}$ was $3.1 \mathrm{yr}$ and $2.1 \mathrm{yr}$, respectively (Table 5). Patients returning to therapy had a median of $20 \mathrm{wk}$ of treatment (16.7 wk and $26 \mathrm{wk}$ for those with PSA levels $<1 \mathrm{ng} / \mathrm{ml}$ and $1-4 \mathrm{ng} / \mathrm{ml}$, respectively), which was followed by a second period off therapy (Table 5). Only 121 of patients on IHT had two returns to therapy postrandomisation, and this was for a median of $19.6 \mathrm{wk}$ (Table 5).

\section{Discussion}

Two observations have considerable clinical importance: (1) a 3-mo period of induction therapy was used in this study, as in SEUG 9401 [2], and (2) patients in the intermittent arm who were on therapy received CPA $300 \mathrm{mg} / \mathrm{d}$ as monotherapy. This intermittent protocol is the first using antiandrogen monotherapy, and the study demonstrated that intermittent monotherapy with CPA
$300 \mathrm{mg} / \mathrm{d}$ was noninferior to continuous therapy in terms of OS. Indeed, the hazard of dying on intermittent therapy was $20 \%$ lower than on continuous therapy in patients with a PSA level $\leq 1 \mathrm{ng} / \mathrm{ml}$ after induction therapy.

The study is reporting early in terms of numbers of deaths, as all randomised patients had been followed for at least $5 \mathrm{yr}$. The death rate was lower than anticipated, and the estimated proportion of patients surviving at $5 \mathrm{yr}$ was $61 \%$, with a median survival time of $6.6 \mathrm{yr}$ compared with the anticipated $4.5 \mathrm{yr}$. By October 2012, there were 525 deaths and 106 deaths were accumulated over the last $2 \mathrm{yr}$ follow-up. Thus a further $2 \mathrm{yr}$ follow-up, at least, would be needed to accrue the additional 133 deaths required to reach the 658 deaths specified in the protocol. In addition, noninferiority of intermittent therapy compared with continuous therapy was demonstrated in terms of OS. There was also no evidence of any difference in terms of PFS, and with an HR of 1.01 (95\% CI, 0.86-1.19), it is clear that noninferiority of IHT compared with continuous therapy can also be demonstrated for PFS. Metastatic status, PSA level at randomisation, Gleason score, and age were independent predictors of PFS, with age 60-74 yr, M0, low Gleason score, and low PSA associated with longer duration of PFS.

In this study, $50 \%$ of patients receiving IHT were off therapy for at least $2.5 \mathrm{yr}$ following initial LHRH therapy, and $28 \%$ were off therapy for $>5 \mathrm{yr}$. These findings support the work of Seruga and Tannock, with data collected from $>1000$ randomised patients indicating that IADT should be regarded as standard therapy [11] for specific patient groups. In 2007, Shaw et al. performed a meta-analysis of 1446 patients from international phase 2 studies and concluded that the duration of biochemical remission after a period of hormone therapy was a durable early indicator of how rapidly androgen-independent PCa and death would occur [12].

In our study, although not significant, more deaths from any cancer occurred in the IHT arm, but more deaths from CVD occurred in the continuous treatment arm. In contrast, although there were no differences between study arms in the domains of the QLQ-C30, side effects were generally less commonly reported in the intermittent arm. Patients on intermittent therapy experienced fewer sexual problems and reported greater sexual activity than patients on continuous therapy. During follow-up, although progressively more patients in the intermittent arm were on 
therapy and sexual activity decreased, sexual activity was still significantly higher than among patients on continuous therapy. Similar results have been reported in SEUG 9401 [2] and in other studies [6,13-15].

In protocol S9346 from Hussein et al. [3], IADT was proven to be noninferior to continuous deprivation in patients with extensive disease; however, intermittent therapy was statistically inferior in patients with minimal disease, suggesting that continuous therapy would be the preferred treatment in this group. In contrast, there was no difference between minimal disease and extended disease in our trial.

\section{Conclusions}

From this study we can conclude that IHT should be considered as the standard therapy for patients who are not suitable for definitive therapy with advanced $\mathrm{PCa}$ because IHT is noninferior to continuous therapy with regard to OS. In addition, IHT is associated with better QoL (ie, sexual life) and lower costs for communities than continuous therapy. This study also showed that an induction period of $3 \mathrm{mo}$ is adequate to sufficiently reduce PSA levels. Based on results from SEUG 9401 [2] and 9901, we can define an optimal candidate for intermittent therapy as a patient with (1) M0, (2) T3, and (3) PSA levels prior to induction therapy $<100 \mathrm{ng} / \mathrm{ml}$ whose PSA decreases to $<4 \mathrm{ng} / \mathrm{ml}$ (preferably $<1 \mathrm{ng} / \mathrm{ml}$ ) after $3 \mathrm{mo}$ of induction therapy. Intermittent therapy is less likely to be beneficial for patients with metastasis and bone hot spots, with high initial PSA levels ( $>100 \mathrm{ng} / \mathrm{ml})$, or with severe pain or extensive disease.

Author contributions: Fernando Calais da Silva had full access to all the data in the study and takes responsibility for the integrity of the data and the accuracy of the data analysis.

Study concept and design: F. Calais da Silva.

Acquisition of data: F. Calais da Silva, F.M. Calais da Silva, Gonçalves, Santos, Kliment, Whelan, Oliver, Antoniou, Pastidis, Marques Queimadelos, Robertson.

Analysis and interpretation of data: F. Calais da Silva, Robertson. Drafting of the manuscript: F. Calais da Silva.

Critical revision of the manuscript for important intellectual content: F. Calais da Silva.

Statistical analysis: Robertson.

Obtaining funding: None.

Administrative, technical, or material support: None.

Supervision: F. Calais da Silva.

Other (specify): None.

Financial disclosures: Fernando Calais da Silva certifies that all conflicts of interest, including specific financial interests and relationships and affiliations relevant to the subject matter or materials discussed in the manuscript (eg, employment/affiliation, grants or funding, consultancies, honoraria, stock ownership or options, expert testimony, royalties, or patents filed, received, or pending), are the following: None.

Funding/Support and role of the sponsor: Ipsen Pharma provided funding for editorial assistance.
Acknowledgement statement: Editorial assistance for this manuscript was provided by Martin Gilmour and Daniella Otway at ESP Bioscience (Crowthorne, UK). The authors are grateful to the patients recruited in this study from the following centres: Portugal: Centro Hospitalar Lisboa Central in Lisbon, Hospital São Marcos in Braga, Centro Hospitalar do Funchal in Madeira, Centro Hospitalar Lisboa Ocidental in Lisbon, Centro Hospitalar do Oeste in Torres Vedras, Centro Hospitalar de Setúbal in Setubal. Spain: Policlinica La Rosaleda in Santiago Compostela, Hospital San Rafael in La Coruna, Hospital General in Elche, Hospital Universitario Puerto Real in Cadiz, Fundacio Puigvert in Barcelona, Instituto Valenciano de Oncologia in Valencia, Hospital del Mar in Barcelona, Hospital Principe de Asturias in Alcalá de Henares. Italy: San Agostino Hospital in Modena, Universita di Napoli Frederico II in Naples, Ospedale Di Circolo e Fondazione Macchi in Varese. Greece: General Hospital in Athens, 3rd IKA Hospital in Athens, Amalia Fleming Hospital in Melissa, Red Cross Hospital in Athens, University of Patras in Patras, Evangelismus Hospital in Thessaloniki, Aristotle University in Thessaloniki. Slovak Republic: Jessenius School of Medicine in Martin, Klinika Lfuk in Bratislava. United Kingdom: St. James University Hospital in Leeds, St. Bartholomews in London. Turkey: SSK Tepecik Hospital in Izmir, Dokuz Eylul University in Izmir, University Medical Ibni Sina in Ankara.

\section{References}

[1] Heidenreich A, Bastian PJ, Bellmunt J, et al. Guidelines on prostate cancer. European Association of Urology Web site. http://www. uroweb.org/gls/pdf/08\%20Prostate\%20Cancer_LR\%20March\%2013th \%202012.pdf.

[2] Calais da Silva FE, Bono AV, Whelan P, et al. Intermittent androgen deprivation for locally advanced and metastatic prostate cancer: results from a randomised phase 3 study of the South European Uroncological Group. Eur Urol 2009;55:1269-77.

[3] Hussain M, Tangen CM, Higano CS, et al. Intermittent (IAD) versus continuous androgen deprivation (CAD) in hormone sensitive metastatic prostate cancer (HSM1PC) patients (pts): results of S9346 (INT-0162), an international phase III trial [abstract 4]. J Clin Oncol 2012;30.

[4] Miller K, Steiner U, Lingnau A, et al. Randomised prospective study of intermittent versus continuous androgen suppression in advanced prostate cancer [abstract 5015]. J Clin Oncol 2007;25.

[5] Tunn U, Kurek R, Kienle E, Maubach L. Intermittent is as effective as continuous androgen deprivation in patients with PSA-relapse after radical prostatectomy (RP) [abstract 1458]. J Urol 2004;171.

[6] Abrahamsson PA. Potential benefits of intermittent androgen suppression therapy in the treatment of prostate cancer: a systematic review of the literature. Eur Urol 2010;57:49-59.

[7] Bruchovsky N, Rennie PS, Coldman AJ, Goldenberg SL, To M, Lawson D. Effects of androgen withdrawal on the stem cell composition of the Shionogi carcinoma. Cancer Res 1990;50:2275-82.

[8] Crook M, O'Callaghan CJ, Ding K, et al. A phase III randomized trial of intermittent versus continuous androgen suppression for PSA progression after radical therapy (NCIC CTG PR.7/SWOG JPR.7/CTSU JPR.7/UK Intercontinental Trial CRUKE/01/013) [abstract 4514]. J Clin Oncol 2011;29(Suppl).

[9] Gray RJ. A class of K-sample tests for comparing the cumulative incidence of a competing risk. Ann Statistics 1988;16:1141-54.

[10] Fine JP, Gray RJ. A proportional hazards model for the subdistribution of a competing risk. J Am Stat Assoc 1999;94:496-509.

[11] Seruga B, Tannock IF. Intermittent androgen blockade should be regarded as standard therapy in prostate cancer. Nat Clin Pract Oncol 2008;5:574-6.

[12] Shaw GL, Wilson P, Cuzick J, et al. International study into the use of intermittent hormone therapy in the treatment of carcinoma of 
the prostate: a meta-analysis of 1446 patients. BJU Int 2007;99: 1056-65.

[13] De la Taille A, Zerbib M, Conquy S. Intermittent androgen suppression in patients with prostate cancer. BJU Int 2002;91:18-22.

[14] Irani J, Celhay O, Hubert J, et al. Continuous versus six months a year maximal androgen blockade in the management of prostate cancer: a randomised study. Eur Urol 2008;54:382-91.
[15] Langenhuijsen JF, Badhauser D, Schaaf B, Kiemeney LA, Witjes JA, Mulders PF. Continuous vs. intermittent androgen deprivation therapy for metastatic prostate cancer. Urol Oncol 2013;31: 549-56.

[16] Benjamini Y, Hochberg Y. Controlling the false discovery rate: a practical and powerful approach to multiple testing. J Royal Stat Soc B 1995;57:289-300.

\section{http://esudavos.uroweb.org}

\section{European Urology Forum 2015}

\section{Challenge the experts}

\section{7-10 February 2015, Davos, Switzerland}

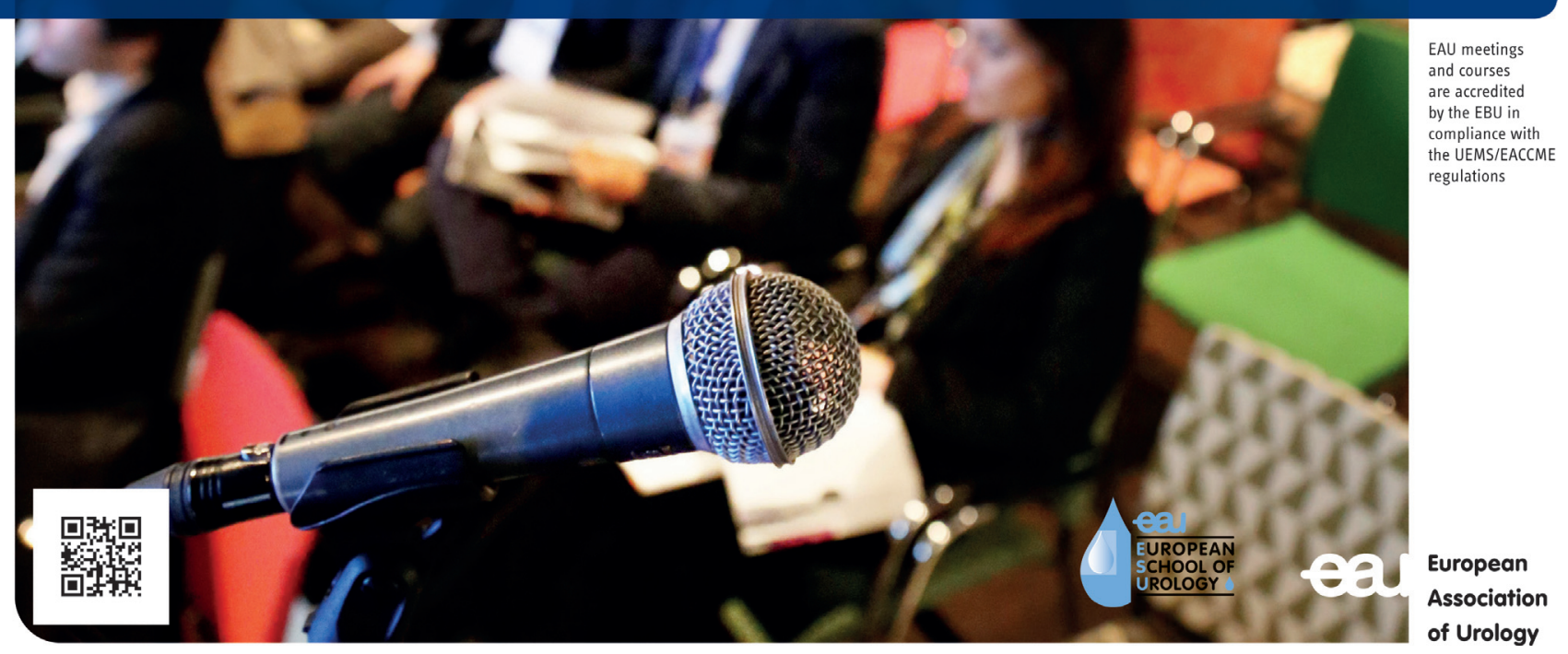

